\title{
Structural steel bond to concrete with waste aggregate
}

\author{
Pawet Ogrodnik ${ }^{1,}$, and Jacek Szulej ${ }^{2}$ \\ ${ }^{1}$ The Main School of Fire Service, Faculty of Fire Safety Engineering, 52/54 Słowackiego St., \\ 01-629 Warsaw, Poland \\ ${ }^{2}$ Lublin University of Technology, Faculty of Civil Engineering and Architecture, \\ 40 Nadbystrzycka St., 20-618 Lublin, Poland
}

\begin{abstract}
The article presents the results of bond tests of B500SP structural steel to concretes subjected to thermal stress. Concretes were designed purely on the basis on waste aggregate made of soft clay pottery with using two types of cements: Portland CEM 32.5R and aluminous cement Górkal 70. In the research was used the method of direct pulling the steel rod out of the concrete cover (Pullout Test). For the tests were prepared four types of concretes: two bases of aluminous cement and two on Portland cement without additions. In the remaining mixtures containing the additive in the form of clinoptilolite, the method of simple weight replacement of the selected type of cement with clinoptilolite in the amount of $10 \%$ was used. Mineral puzzolana additives are intended to modify the phase composition of hardened cement slurry towards reducing the portlandite and changing the $\mathrm{CaO} / \mathrm{SiO} 2$ ratio in the $\mathrm{C}-\mathrm{S}-\mathrm{H}$ phase. The results of the tests confirmed that the bond of the selected steel type to concrete on the recycle aggregate does not differ from the results achieved with natural aggregate. It was also confirmed that addition of clinoptilolite to concrete with Portland cement has beneficial effect when it is subjected to thermal stress.
\end{abstract}

\section{Preface}

So far, the cooperation of steel and concrete in ferroconcrete constructions was analysed multiple times due to its practical significance. Many physical, chemical, and mechanical factors impact the grip of rebars, including friction working on the point of contact of both materials $[1,2]$. The grip is also influenced by many technological factors. In the case of ribbed bars, a very notable factor influencing the grip are mechanical interlocks, with strength the greater the asperity of the bar's surface $[3,4]$. Adhesion is also impacted by the shape of aggregate used in the concrete. Due to the decrease in construction aggregates in areas of natural resources, they often have to be transported long distances. This results in an increase in prices, at the same time causing an increase in interest in aggregates originated from recycling.

\footnotetext{
${ }^{*}$ Corresponding author: pogrodnik@sgsp.edu.pl
} 
A developing direction of research is the usage of ceramic materials as recycled aggregate for concrete. Red ceramics in the form of bricks, breeze-blocks or roof tiles, as well as white ceramics (tableware, sanitary ceramics, electrical isolators), are non biodegradable materials, and their disposal is highly problematic. Studies conducted by [5, 6] show that concrete based entirely on white ceramic aggregate does not have different physical and mechanical properties from concrete made of natural aggregate. In the research conducted by $[7,9]$, the material properties of clay cement and ceramic aggregate based concrete were compared to those of concrete made with natural aggregate. The samples were annealed in the temperature of $1000^{\circ} \mathrm{C}$. In contrast to samples of concrete with traditional aggregate the ones with ceramic aggregate retained their shape, consistency, and did not show any flaws and signs of cracking. In spite of losing some of their durability, the second type of samples continued to show high endurance to stretching and pressing. The conducted research shows that in the case of concrete with clay cement and ceramic aggregate it is possible to eliminate the phenomenon of concrete chipping off by introducing an aerating addition. This addition would also increase the durability of the concrete in comparison to samples without such an additive, as well as lowering the reduction of endurance in the case of heating the samples to high temperatures, according to the assumed "temperature-time" breakdown. Research conducted so far confirms that recycled aggregate derived from ceramic sanitary fittings can provide an alternative to natural aggregate, however, the lack of complex tests of the primary traits of concrete impede the assessment of its usefulness.

\section{Materials and methods}

\subsection{Characteristics of materials for making samples}

To prepare the concrete, waste from sanitary ceramic obtained from waste products from a Polish factory of sanitary fittings was used. The ceramic waste was shredded into two fractions: $0 \div 4 \mathrm{~mm}$ and $4 \div 8 \mathrm{~mm}$. At the same time, the resistance to crushing at the base was specified. The study was conducted on the aggregate of the $4 \div 8 \mathrm{~mm}$ fraction. The average indicator of crushing was $6,75 \%$, which means that the aggregate from the sanitary ceramic waste is resistant to crushing. When composing the composition of concrete mixes it was assumed that in all cases there would be a constant value of the water-binder ingredient of $\mathrm{w} / \mathrm{s}=0,4$. This proposition was used mainly to limit the content of capillary pores in the structure of the cement's warp. The composition of the basic mixes without additive was determined by the three equation method, while the composition of the other concretes was an amendment of the basic mixtures. Recycled ceramics were used as the aggregate. The weight proportions of all the ingredients of the concrete mixtures are presented in Table 1.

Table 1. Weight compositions of concrete mixes in $\left[\mathrm{kg} / \mathrm{m}^{3}\right]$.

\begin{tabular}{|c|c|c|c|c|c|c|}
\hline \multirow{2}{*}{$\begin{array}{c}\text { Concrete } \\
\text { series }\end{array}$} & \multicolumn{2}{|c|}{ Cement } & \multicolumn{2}{c|}{ Aggregate } & \multirow{2}{*}{ Addition } & \multirow{2}{*}{ Water } \\
\cline { 2 - 5 } & $\begin{array}{c}\text { Portland } \\
\text { CEM I 32,5R }\end{array}$ & $\begin{array}{c}\text { Aluminum } \\
\text { Górkal 70 }\end{array}$ & $\begin{array}{c}\text { Fraction } \\
\text { 0-4mm }\end{array}$ & $\begin{array}{c}\text { Fraction } \\
\text { 4-8mm }\end{array}$ & & \\
\hline PB-00 & 488,0 & - & 997,14 & 398,86 & - & 199,0 \\
\hline GB-00 & - & 488,0 & 997,14 & 398,86 & - & 199,0 \\
\hline PK-10 & 439,2 & - & 997,14 & 398,86 & 48,8 & 199,0 \\
\hline GK-10 & - & 439,2 & 997,14 & 398,86 & 48,8 & 199,0 \\
\hline
\end{tabular}


Evaluation of the phase composition of selected cements was made based on the results of diffraction analysis, which is presented in Fig.1.

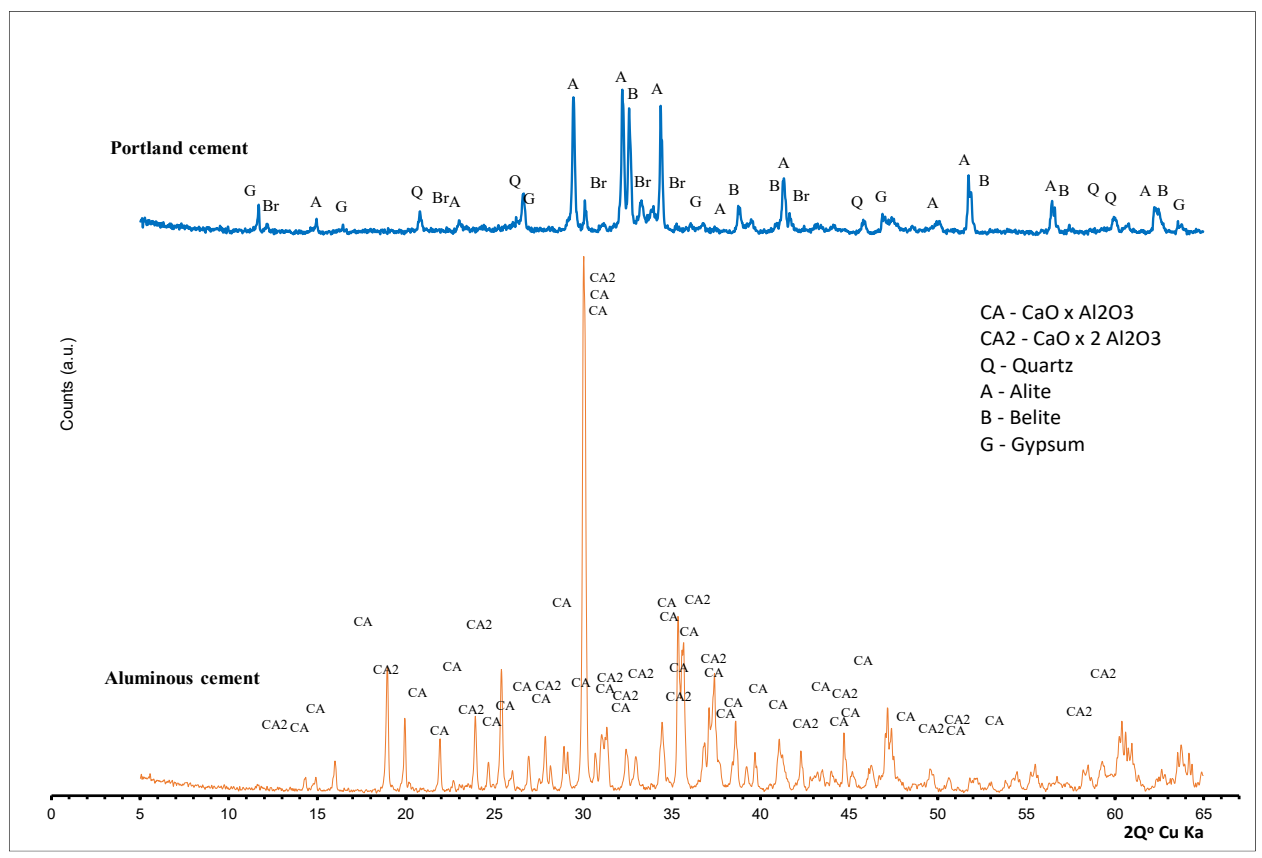

Fig. 1. Diffraction image of mineral composition of Portland cement I $32.5 \mathrm{R}$ and aluminum Gorkal 70.

The predominant crystalline phase present in the aluminum cement is calcium monoaluminate $(\mathrm{CA})$ accompanied by calcium deconate $\left(\mathrm{CA}_{2}\right)$. The first was identified thanks to its distinctive interplanar distances $\mathrm{d}_{\mathrm{hkl}}=5.956 ; 5.529 ; 4.687 ; 4.052 ; 3.718 ; 3.309$; $3.199 ; 2.974 ; 2.911 \AA$, the second $\mathrm{d}_{\mathrm{hl}}=6.185 ; 4.448 ; 3.506 ; 2.850 ; 2.601 \AA$. In the case of portland cement, the main ingredients are alite $\mathrm{C}_{3} \mathrm{~S}$ and belite $\mathrm{C}_{2} \mathrm{~S}$, which are the main components of clinker and $\mathrm{C}_{3} \mathrm{~A}$ triacellate, as well as $\mathrm{C}_{4} \mathrm{AF}$ brownmillerite (four-calcium aluminum ferrate).

Ribbed steel of the B500SP type, according to PN-H-93220:2018-02 class A-IIIN, with a diameter of $\varnothing 10 \mathrm{~mm}$ and length of $720 \mathrm{~mm}$ was used to reinforce the samples. The steel's endurance parametres are presented in Table 2.

Table 2. Strength properties of structural grade steel B500SP.

\begin{tabular}{|l|c|c|}
\hline \multicolumn{1}{|c|}{ Description } & Symbol & Value \\
\hline The limit of plasticity, [MPa] & $\mathrm{f}_{\mathrm{yk}}$ & $500 \div 625$ \\
\hline $\begin{array}{l}\text { The ratio of the characteristic tensile strength } \\
\text { to the yield strength, [-] }\end{array}$ & $\mathrm{f}_{\mathrm{tk}} / \mathrm{f}_{\mathrm{yk}}$ & $1,15 \div 1,35$ \\
\hline Minimal elongation, [\%] & $\mathrm{A}_{5}$ & 16,0 \\
\hline
\end{tabular}

\subsection{Samples for testing}

In order to test the adhesive friction of steel to concrete, cylindrical samples with a steel rod were prepared. The size of the samples was determined on the basis of previously performed tests $[10,11]$. The samples were made in special moulds compromised of basic concrete of the PB-00 series, as well as concrete with a klinoptilolith addition of the PK-10 
and GK-10 series. The moulds were cylindrical in shape, $150 \mathrm{~mm}$ high and with a base diameter of $100 \mathrm{~mm}$. The size of the samples was selected to ensure the temperatures outside of the sample and in the contact point of concrete and steel would even out quickly, when conducting thermal stress tests. The appearance of the samples is presented in Fig. 2.

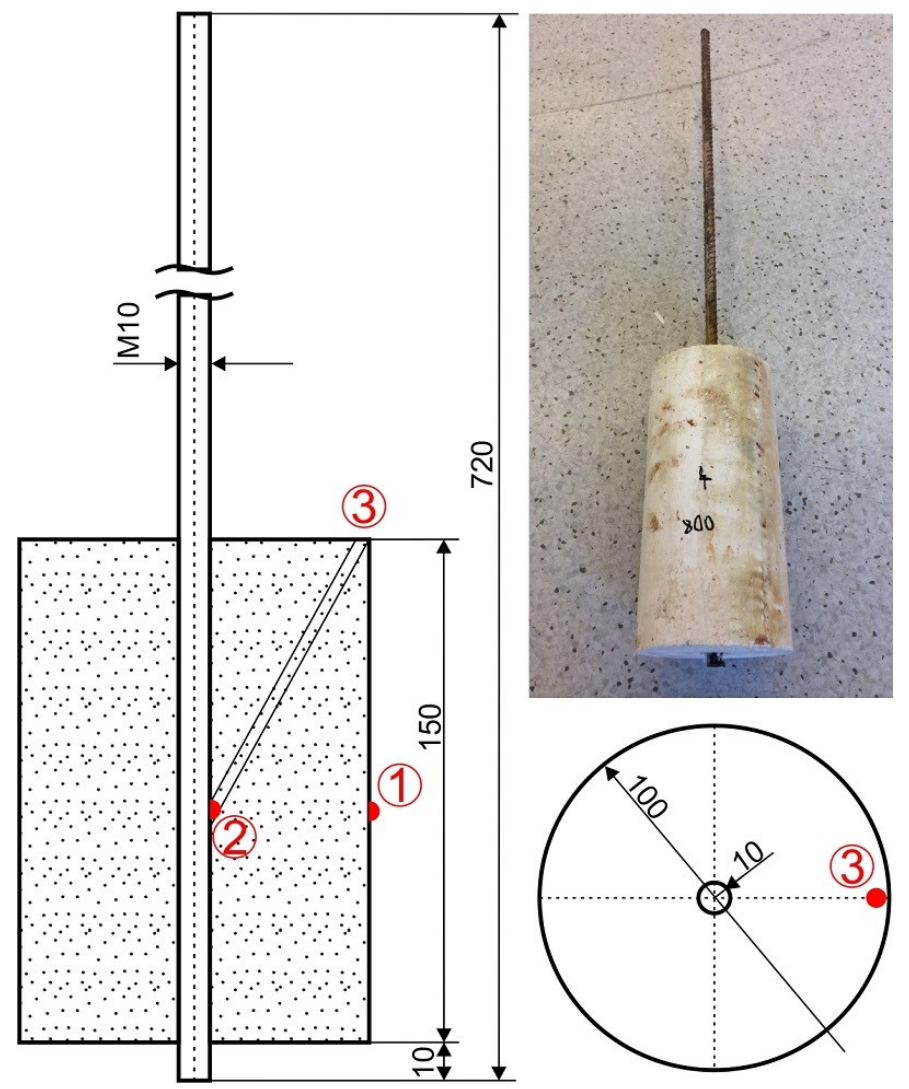

Fig. 2. Test sample cross-section, where: 1- external thermocouple, 2 - internal thermocouple, 3 - channel for introducing a thermocouple.

After bracing the samples, they were placed, along with the moulds, in a chamber with controlled humidity of $95 \%$ and the temperature of $18^{\circ} \mathrm{C}$. On the presented figure of the sample (Fig. 1A), points 1 and 2 indicate the places where the thermal measuring devices were placed during thermal stress tests. Tubule 3 was created during the bracing in order to introduce thermocouple. After 48 hours, the samples were demoulded and once again placed in the climatic chamber. They were then stored in the laboratory in room temperature for three months, until they were conducted to thermal tests.

\subsection{Thermal loading of samples}

The annealing of the samples was carried out in a five chamber PK1100/5 type electric furnace. The workstation was equipped with a control and registering system, and a PC along with software that enabled changing the temperature during the study, as well as monitoring the temperature during the heating of the samples. Type $\mathrm{K}$ thermocouple $\mathrm{NiCr}-$ $\mathrm{Ni}$ ) was used to measure the temperature. During the study the aim was to keep the temperature distribution close to the thermal conditions of a standard (normal) fire. That is why, as the basis it was adopted that in the environment surrounding the construction, the 
regular distribution "temperature-time" according to norm occured [12]. According to the plan of the study, the samples were heated to the temperatures of $400 \mathrm{C}, 600 \mathrm{C}$ and $800 \mathrm{C}$, in batches of five samples in all given temperatures. During the the tests, the "temperaturetime" distribution was adopted, corresponding to the temperature distribution in a $15 \mathrm{~mm}$ thick concrete slab.

After reaching the temperature established in the experiment's plan, it was kept at a constant level for a period of about 30 minutes until the external temperature reached that of the point of contact of the bar and concrete. During this time, the temperature in the point of contact and the surface of the sample was monitored. The temperature profile is presented in Fig. 3.

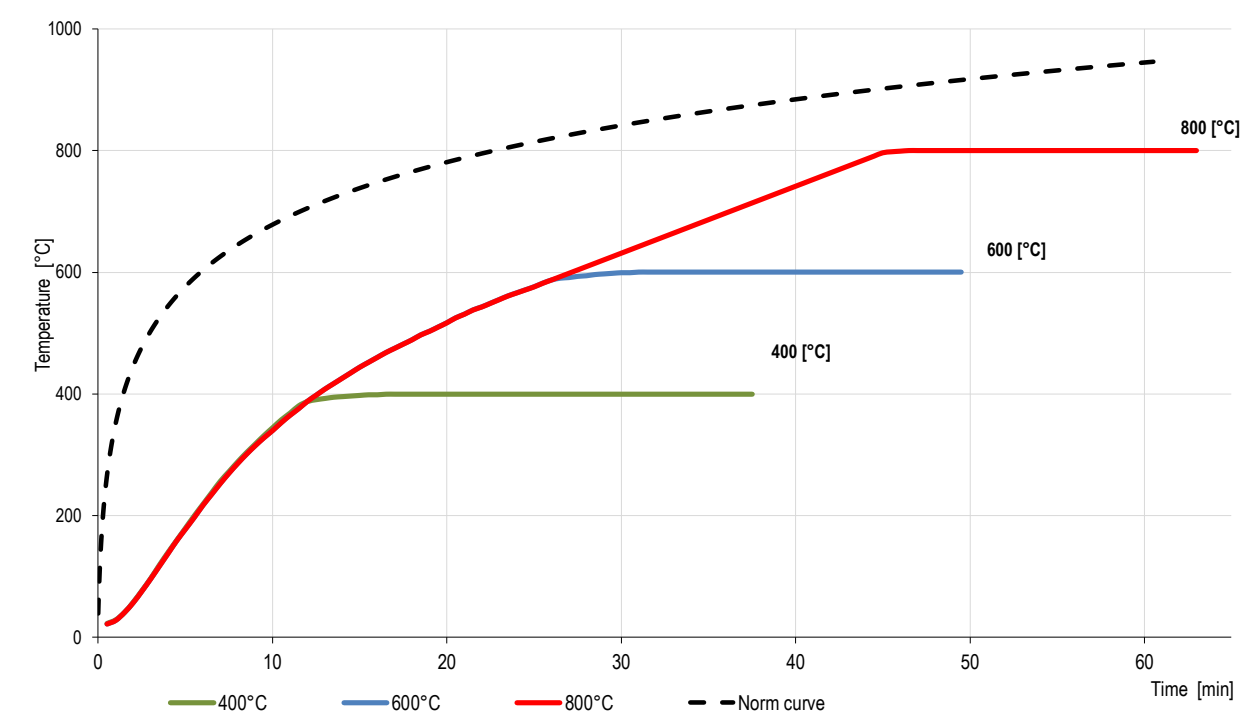

Fig. 3. The temperature distribution assumed in the studies with the heating time indicated, where: 1 - external thermocouple, 2 - internal thermocouple, 3 - channel for introducing a thermocouple.

After annealing, the samples remained in the furnace for 48 hours, until completely cooled. The prepared samples were then subjected to endurance tests (removing the rod).

\section{Tests of steel adhesion to concrete}

To perform the research, a VEB Thuringer Industriewerk Rauenstein type FPZ 100/1 ripper was used, which enabled the use of a static force when stretching or pressing, as well as maintaining it in a vertical state on a constant level. When testing the grip of the concrete and rod via pull-out method, a range of I/III was used, as it carries out crosshead movement at $0,021 \div 0,84[\mathrm{~mm} / \mathrm{min}]$.

Each sample was placed in the workplace and a force necessary to pull out the rod out of concrete was exerted upon them. In the study a maximum force of (Fcr), neccessary to extract the steel rod from the concrete was assigned. The obtained data is presented in Fig.4 and Fig. 5. 


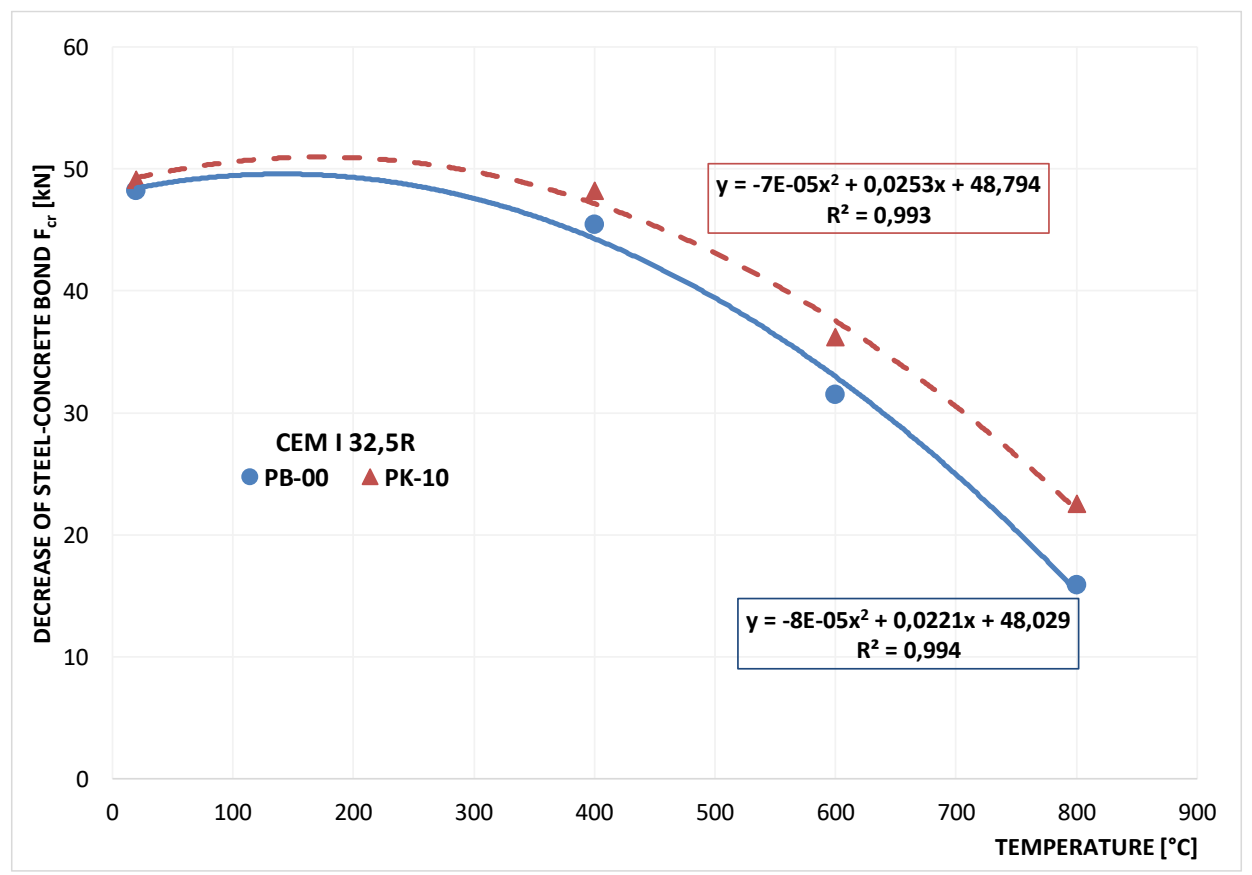

Fig. 4. The average value of adhesion force of B500SP steel to concrete based on Portland cement CEM I 32.5R.

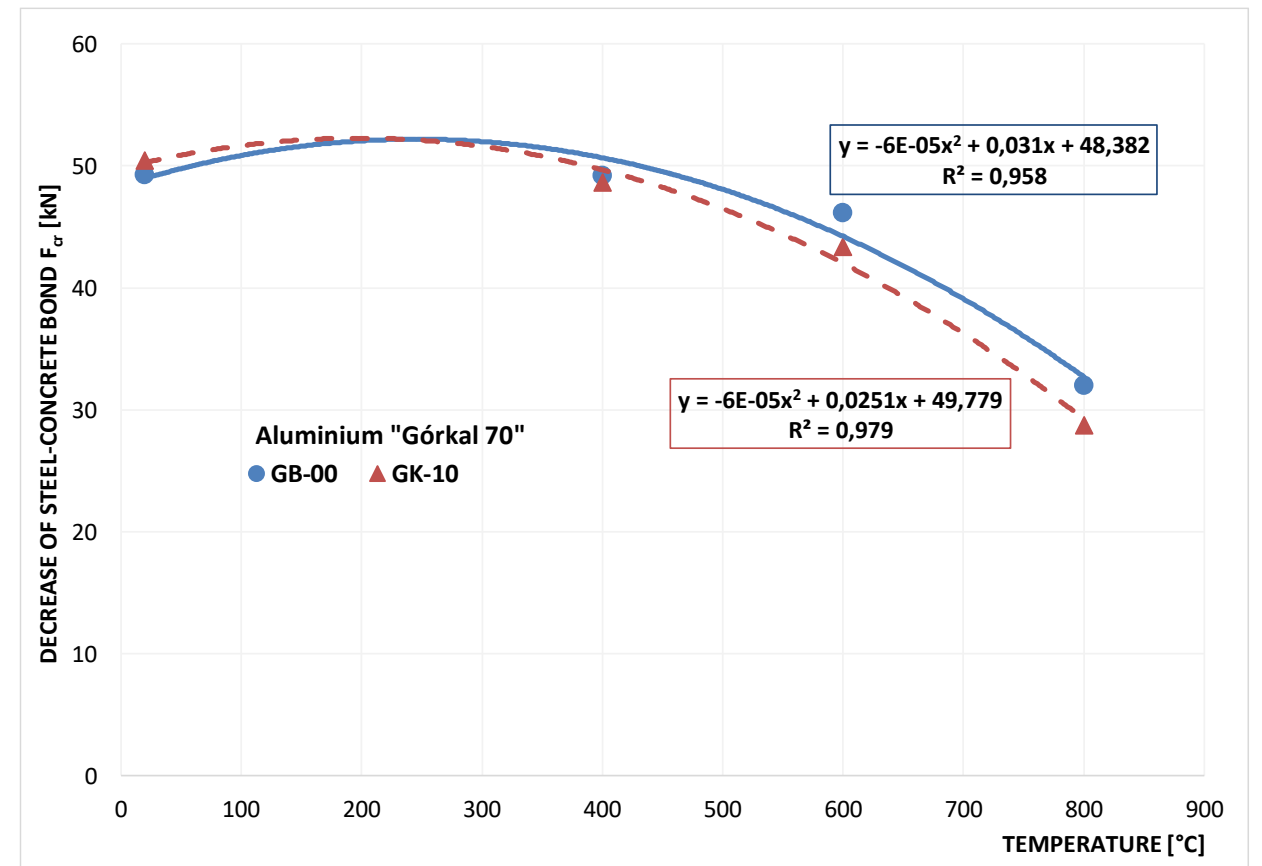

Fig. 5. The average value of adhesion force of B500SP steel to concretes based on "Górkal 70" clay cement. 


\section{Summary and conclusions}

Comparing the average results of the adhesive friction of B500SP steel and concretes based on CEM I 32,5 R portland cement, we can observe that along with the rise of temperature to which the samples were heated, the value of the grip is lower for both Pa- 00 and PK-10 cement. Concrete with the addition of klinoptilolith consistently showed a higher adhesive friction in comparison to basic PA-00 samples. The difference grew along with the temperature of annealing. Samples that were not annealed had a similar average grip value, however, this rose by about $41.9 \%$ for PB-00 samples at $800 \mathrm{C}$. The difference was lower at $400 \mathrm{C}(6,2 \%)$ and $600 \mathrm{C}(14,8 \%)$. In comparison to tests [9-11], in which $2-8 \mathrm{~mm}$ sized gravel aggregate and vistulian sand was used, the average value of adhesive friction for B500SP steel and concrete, based on CEM I 32,5R cement and recycled ceramic aggregate, it is much higher in all researched temperatures. What is important, their decrease caused by thermal stress is also significantly lower. In tests [13] at the temperature of $600 \mathrm{C}$, the decrease of grip of B500SP and the designed concrete was about $44 \%$, while at $800 \mathrm{C}$ it was $83 \%$. For PK-10 concrete it was 26\% (400C) and 54\% (800C) respectively.

In the case of samples made of clay cement Góral 70, along with the rise of heating temperature, the grip of B500SP steel to GB-00 and GK-10 cements decreases. In these concretes, with the acception of samples that were not annealed, the addition of klinoptilolith caused a decrease of average adhesive friction, however these differences were not large. While at $400 \mathrm{C}$ it is about $1 \%$, this value increases at $600 \mathrm{C}(6,5 \%)$ and $800 \mathrm{C}$ $(11,2 \%)$. Between $400 \mathrm{C}$ and $600 \mathrm{C}$ the decrease of adhesive friction between B500SP steel and GA-00 and GK-10 cement is relatively low. Generally, in both Pa-00 and PB-10, as well as GA-00 and GK-10 concretes, the decrease of adhesive friction to b500SP steel is characterised by a low dynamic with the increase of heating temperature.

\section{References}

1. P.D. Morley, R. Royles, Fire Saf. J. 2, p.243-255 (1980)

2. X. Fu, D.D.L. Chung, Cem. Concr. Res. 27, p.1811-1815 (1997)

3. J.H.H. Fellinger, A. Jołop, D. Uijl, Bond of pretensioned strands in fire exposed concrete. Bond in concrete - from research to standards (Budapest, 2002)

4. Y. Auyeung, P. Balaguru, L. Chung, ACI Materials Journal 97, p. 214-220 (2000)

5. I. Guerra, I. Vivar, B. Liamas A. Juan, J. Moran, Waste Manag. 29, 643 (2009)

6. J. García-González, D. Rodríguez-Robles, A. Juan-Valdés, J. M. Morán-Del Pozo, M.I. Guerra-Romero, Environmental Technology 36(23), 3050 (2015)

7. P. Ogrodnik, J. Szulej, Constr. Build. Mater. 157, 913 (2017)

8. A. Halicka, P. Ogrodnik, B. Zegardło, Constr. Build. Mater. 48, 300 (2013)

9. P. Ogrodnik, B. Zegardło, M. Radzikowska, Chemical Industry. 96 (5), 1102 (2016)

10. Z. Bednark, P. Ogrodnik, R. Kamocka-Bronisz, S. Bronisz, Study of fire temperatures and shock cooling influence on the bond strength between steel B500SP and BSt500S to concrete. Proceedings (Pożarna Ochrana, 21th International Conference on a Fire Protection, Ostrava, 2012)

11. Z. Bednarek P. Ogrodnik D. Pieniak, Eksploat. Niezawodn. 3(47), pp. 67-78 (2010)

12. PN-EN 1363-1: 2001 - Fire resistance test. Part 1: General requirements.

13. Z. Bednarek, R. Kamocka-Bronisz, P. Ogrodnik, S. Bronisz, Safety and Fire Technique No. 1, pp.67-73 (2013) 